\title{
APROXIMACIÓN A LA ADMINISTRACIÓN DE JUSTICIA EN LOS ESTADOS UNIDOS DE COLOMBIA: CIUDADANÍA, IDEOLOGÍA Y PRÁCTICAS EN EL CASO DEL ESTADO SOBERANO DE BOLÍVAR, 1863-1886
}

An approach of the administration of justice in the United States of Colombia: citizenship, ideology, and the practices in the case of the Bolivar sovereign state, $1863-1886$

Luis Edgardo Luna González²

\section{RESUMEN}

Este artículo de reflexión es un intento por establecer como era administrado el aparato de justicia institucionalizado en el Estado soberano de Bolívar (18631886) en los Estados Unidos de Colombia, y la relación directa de este con la transformación del concepto de ciudadanía. El periodo motivo de análisis se caracteriza por la imposición de la corriente del pensamiento político denominada liberalismo y es, justamente, desde esta matriz filosófica que se desenvuelven los distintos procesos de construcción y orden del Estado. El aparato jurisdiccional esta inevitablemente ligado a esta concepción, de tal manera que se demuestra como las instituciones, los sustentos doctrinales y la organización interna de los distintos mecanismos de acción procedimental para la "declaración del derecho", se constituyeron en una expresión directa de este paradigma.

Palabras clave: Derecho sustantivo; derecho procesal; liberalismo; justicia; jurados de conciencia.

\section{ABSTRACT}

The following essay analyzes how the judicial apparatus institutionalized in the Sovereign State of Bolivar (1863 - 1886) was managed in The United States of

\footnotetext{
${ }^{1}$ Artículo de investigación tipo 2: de reflexión (clasificación COLCIENCIAS).

${ }^{2}$ Abogado e Historiador. Magister en Conflicto social y Construcción de paz. Diplomado en Derecho Constitucional Colombiano. ORCID: https://orcid.org/0000-0002-5807-7348 E- mail: luislunag30@ hotmail.com
} 
Luis Edgardo Luna González

Colombia, and the direct relation of such with the transformation of the concept of citizenship. The period which is the focus of the analysis is characterized by the imposition of the political thought trend named liberalism, and it is precisely from this philosophical position that the different processes of construction and order of the state are developed from. The jurisdictional apparatus is inevitably linked to this conception, to such extent that it shows how the institutions, doctrinal arguments and the internal organization of the different mechanisms of procedural actions for the "declaration of rights", represented a direct expression of such doctrine.

Keywords: Substantive law, procedural law, liberalism, justice, juries of conscience.

\title{
1. Diálogos contextuales en el país de las leyes: el foro de la justicia
}

\author{
"La vida social no puede ser concebida sin que sus relaciones \\ sean reguladas por la seguridad \\ que tengan todos i cada uno de los asociados de que sus personas, \\ su honra i su propiedad son respetados; \\ sin que la amenace ningún atentado ora parte de este Gobierno, \\ ora de los particulares. Sin la seguridad absoluta la idea del progreso desaparece, \\ i con ellas las esperanzas de la anhelada felicidad".
}

Informe del Procurador General del Estado. Diario de Bolívar. Cartagena, 22 de agosto de 1878.

Pasarían años antes de que un libro como An Introduction to the Principles of Morals and Legislation (Bentham, 1789/1907) pudiera ser consultado sin que la primacía panóptica de la censura, ejerciera el respectivo efecto en los círculos intelectuales de principios del siglo XIX colombiano, que aún veían en Bentham una especie de oráculo mal entendido ${ }^{3}$. El inglés, que antes de su muerte había pedido expresamente que su esqueleto vestido fuera expuesto en una vitrina de una de las salas de la University College de Londres, había dicho ni más ni menos que la función de los Estados tendría que ser la obtención de la mayor felicidad para el mayor número de los individuos (Critchley, 2008 Pág. 32).

Esta expresión, que para los poco más de dos millones de granadinos no pasaba de ser ignorada, hirvió sin embargo la imaginación de un círculo de prestigiosos escritores, que se hacían llamar liberales y que pretendían sentar las bases para la modernidad, con todo y las contradicciones intrínsecas de esta. Pero Bentham, insistió con ímpetu sobre otros asuntos. Habló de libertad, de democracia, y de cómo debían servir las leyes para evacuar el molesto mal de las infracciones a las normas, que los legisladores se esmeraban tanto en elaborar. Leyes, normas, códigos, procedimientos forjados desde una realidad física

\footnotetext{
${ }^{3}$ Las doctrinas sobre política y legislación de Bentham constituyeron el primer gran acervo de las nuevas concepciones del Estado enseñados en las universidades en Colombia luego de la independencia, especialmente en las clases altas. El gran impulsor inicial de la teoría Utilitarista de Bentham fue el General Santander.
} 
determinada, habrían de ser poco menos que perfectas para enraizar en los elementos humanos, y hacer florecer la civilidad ${ }^{4}$.

Un país civilizado, fue justamente lo que se atrevieron a proponer los constituyentes del 63 cuando ya Mosquera, intuía que su pelea por los poderes omnímodos estaba perdida, según corría a voces por la Villa de Rionegro (Jimeno, 2006. Pág. 167-191). Lo cierto era que cada cambio constitucional fungía como un simplificado recurso de refundación moral de la Nación: expectativas, metas ciertas, y un evidente anhelo de imitación europea, daban al discurso radical un severo arreglo según reglas nuevas que se parecían demasiado a los librillos que leían los suramericanos en las cátedras de jurisprudencia de Francia e Inglaterra (Martínez, 2001). Se invocaba justicia a la manera no de un canto operático, sino como un mesurado llamado en tierras desconocidas, tierras donde lo que menos había eran ángeles precursores.

Así pues, en este panorama tan desconcertante, la Administración de justicia del Estado Soberano de Bolívar decimonónico, no podía entonces estar sino llamada a ser la expresión natural de una Nación con pretensiones de modernidad. Sin embargo, ese progreso material que debía ser también moral, signado por elocuentes tratados de derecho, corría el riesgo de volverse una avalancha desbordada de buenas intenciones, como cuando el análisis contextual de la realidad de la Federación, daba cuenta de lo imprevisible que era tratar de conciliar la diversidad cultural, la segmentación racial, política y económica, con la idea improrrogable de una ciudadanía que se impartiera desde la igualdad ante la justicia y la ley. No solo era cuestión de propaganda: el éxito de este nuevo renacimiento habría de estar constituido por la mediación de un órgano jurisdiccional que se comportara como un ente soberano, imparcial, y que vinculara al nuevo ciudadano al manejo de los asuntos públicos, incluso en la asignación del derecho. Las codificaciones constitucionales y normativas, debían expresar las valoraciones políticas y éticas, y, en suma, en ellas residían las pautas para el establecimiento de la paz (Aguilera, 2001. Pág. 8-11)

En efecto, el individuo de ese país en transformación fue imaginado desde las tertulias intelectuales, los cafés y los conciliábulos para que fuera capaz de justificar la acción del Estado, mediante su intervención directa en la esfera de lo público, abriendo así los espacios para una legitimidad que vivificaba a su vez, la misma existencia de la sociedad. En este contexto, las discusiones actualizaron las controversias sobre la inconveniencia de la pena de muerta, los castigos infamantes, castigos corporales, exilio forzoso, y en general, sobre

\footnotetext{
${ }^{4}$ Civilizar la sociedad para construir un nuevo paisaje material y moral fue un pensamiento recurrente entre los pensadores de la Nueva Granda para oponerse al viejo sistema colonial, cuyo epitome era la destrucción posterior a las guerras de independencia. Para examinar el sistema de estas teorías políticas en este periodo ver: MARTíNEZ, Fréderic. "En los orígenes del Nacionalismo Colombiano: Europeísmo e ideología nacional en Samper, Núñez y Holguín (1861-1894). En: Banco de la República. Boletín cultural y bibliográfico. No. 39. Vol. XXXII Editado en 1996. 
Luis Edgardo Luna González

el exceso normativo que acarreaba confusiones, contradicciones, y que degeneraba en una percepción bárbara del sistema (Mayorga, 2001. Pág. 3-7).

En tal sentido, es apropiado pensar que el gran esfuerzo de la política del radicalismo decimonónico, con la influencia de Bentham y otros intelectuales, nacionales y extranjeros, fue la construcción de una nueva legitimidad de la Administración de Justicia, con lo cual se le otorgaba al individuo no solo el derecho si no el deber de su intervención en los asuntos públicos. Así se pensó cuando una figura de fuerte arraigo en las instituciones jurídicas inglesas como la de los jurados de conciencia, se importa a los Estados Unidos de Colombia a través de los Estados Soberanos como el de Bolívar, con las más disímiles consecuencias, que encajarían según los más pesimistas comentaristas de la época, en una perfecta distopía; una que seguramente pudo horrorizar a Bentham desde la soledad de su urna en la University College de Londres.

\section{Constituciones, representaciones, localias y proyectos sistémicos}

La oportunidad para que los liberales de 1878 libraran una venganza en Cartagena, se dio sorpresivamente el 8 de diciembre. La elección de Aquileo Parra para la presidencia de la República, tan cuestionada como reprobada, puso en jaque a los grupos conservadores del Estado Soberano de Bolívar y en la capital, se esparcía un drama previsible. La noche del mencionado día, en el Paseo público o Camellón, un grupo de conservadores morían a manos de liberales enfurecidos, creídos de una conspiración en sus propias narices. El acto de represalia constituyó una prueba de fuego para la Administración de Justicia local, como bien lo intuyeron el Gobierno de Rafael Núñez, y la presidencia del Tribunal Superior del Estado, en cabeza de Eloi Pareja.

La investigación y el proceso para hallar a los culpables, asunto de múltiples connotaciones, se desarrollaría con tanta celeridad, que el 23 de junio de 1879 ya había sentencia condenatoria para los culpables, y poco después, en un anónimo que circularía por los barrios de San Diego y los alrededores, se exaltaría la presteza del Procurador General de Estado, Carmelo Arango, y del Tribunal Superior, para resolver sobre la autoría material del macabro hecho. Todas las actuaciones daban la impresión de que los alegatos habían sido prontamente atendidos: la justicia se había hecho. Capturados a los asesinos y prolongada una suerte de paz que se parecía más a la serena espera antes de una última batalla, había porque creer en aquella y en quienes la ejercían (Lemaitre, 1983. Pág. 255262).

Estos procedimientos tan singularmente rápidos, no dejaban sin embargo de contrastar severamente con la realidad cotidiana que nos exhibían los Jueces, Gobernadores, Procuradores y Magistrados en sus informes anuales. Signada con todos los defectos que 
se le pudieran atribuir a un ente Federal, fue, no solo uno de los más cuestionados, si no que evidenció trágicamente un problema más de fondo: el proceso lento e inconexo en que se desarrollaron la cohesión social, y dentro de esta, las contradicciones en que se incurría a la hora de establecer lo esencial de la representación del individuo-ciudadano, justo cuando las revoluciones liberales se instituían, marcando si se quiere, una tendencia a la protección extensiva de privilegios libertarios y de inclusión social, muchos de los cuales, eran reprendidos por partidos locales como altamente inconvenientes.

Años atrás, una Constitución de corte eminentemente libertaria, había levantado algunos pilares para la consecución de aquello que se llama severamente ciudadanía miscelánea. Pero estas reivindicaciones, en las nuevas circunstancias, marcarían desacuerdos dogmáticos y de aplicación puramente ejecutiva (López, 1999. Pág. 74-104). Los principios rectores en los que se basaron estas prácticas, habían sido imperativos desde cuando en la Constitución del 60 del Estado Soberano de Bolívar, constitutivo de la Unión, se promulgaron aquellos desde la operatividad de los principios liberales, haciendo construir paradigmas que intentaban alejarse del orden inquisitivo y centralizado del viejo sistema colonial ,que perduro consistentemente muchos años después de entrada la república 5 .

En el Título 4 "De las garantías y deberes", se dio por sentada una noción básica de carácter democrático, como elemental regla al sujeto procesal y garantía de justicia, estableciendo así en el Artículo 11, que el Estado garantiza a sus miembros la "seguridad personal; de ningún modo que ningún boliviano puede ser privado de su libertad, sino por un hecho punible declarado como tal por leyes preexistentes o para ser juzgado cuando conforme a las mismas leyes se decrete su prisión por estar acusado o sospechado de haber cometido alguno de esos hechos punibles. Queda expresamente prohibida la prisión por deudas" (Num.2).

En esta misma línea se deja claro el establecimiento del juicio por Jurados "tanto, para declarar con lugar el juzgamiento, como para calificar los hechos punibles, i declarar quienes son responsables de su comisión, en todos los casos en que se proceda, por delito o crimen, castigado con pena corporal o con la perdida de la libertad del individuo por más de un año. Exceptuase los juicios por delitos políticos, los de responsabilidad contra los funcionarios públicos por mal desempeño en el ejercicio de sus funciones i los que expresan las atribuciones $1^{\mathrm{a}}$ i $2^{\mathrm{a}}$ del artículo 61” (Núm. 6).

\footnotetext{
${ }^{5}$ Esta ciudadanía miscelánea, consistía principalmente en la formulación de un tipo de status político que a la vez que propendía por un individualismo expresado en el discurso de protección y consignación de derechos individuales, también consistía en un interés por integrar al ciudadano a la responsabilidad del que hacer público. De lo que se trataba era de una combinación teórica entre el liberalismo individualista egoísta- del hacer lo que por naturaleza me es dado hacer, y el individualismo comprometido, es decir, el uso de la libertad dirigida la participación en la res pública.
} 
Luis Edgardo Luna González

Más importante aún, la afirmación de "la igualdad de los derechos individuales frente a la ley por lo cual no puede establecerse diferencia proveniente de fuero, privilegio, distinción profesional o clase" (Num.7), y la "necesidad de la inviolabilidad de todos los escritos privados con las restricciones que establezcan las leyes en los casos en que su examen sea necesario en juicio como prueba de un delito o de una acción civil” (Num.8).

La abolición de la pena capital por delitos cometidos "contra las leyes del Estado" (Artículo 12), la exoneración del testimonio en "causa criminal contra sí mismo, ni contra su consorte, ascendientes, descendientes, o hermanos" (Artículo 14), el establecimiento concreto de la Jurisdicción ejercida por "el Tribunal superior del Estado y por los demás Tribunales y Juzgados que la ley establezca" (Artículo 57), y la implantación de la figura del Ministerio Pública el cual era ejercido "por un Procurador, elegido directamente por el pueblo y por los demás empleados subalternos que señale la ley (Artículo 64)", realzan el carácter fundamentalmente garantista de esta Constitución (Mendoza, 1996. Pág. 186-191).

La última Carta política del Estado Soberano de Bolívar, dada el 1 de abril de 1865 y expedida por la Convención del Estado, disponía en los mismos términos el Aparato jurisdiccional y le daba la calidad de ciudadanos a "los bolivianos mayores de veintiún años, o que sin llegar a esta edad sean o hayan sido casados o legalmente emancipados" (Artículo 11), haciéndolos por este status "electores y elegibles para los puestos públicos pudiendo la ley exigir para estos últimos cuando lo estime conveniente el requisito de saber leer y escribir" (Articulo 14).

En esencia, estas particularidades cumplían en el papel una consignación superior, constitutiva del modelo político que se estaba gestando y que abogaba por desarmar el arquetipo anterior. Esta perspectiva provoco una puesta en escena en donde al ciudadano del común, se le insistía en hacer uso de la confianza que el Estado le brindaba en la difícil tarea de construcción de la Nación colombiana. Estos intentos de crear un sistema eficiente tropezarían continuamente con por lo menos tres grandes problemas: la incapacidad de funcionar como una rama con presencia verdaderamente estatal, de responder a la demanda de los asuntos, y la de suscitar la confianza pública.

Fue justamente esta camisa de fuerza la que se constituyó en el blanco de los ataques a los radicales, y que el fondo no eran más que ataques contra lo que muchos de talante más conservador, consideraban el desorden de la República, uno que año tras año no traía sino pena y pobreza.

¿Que denotan entonces estas prerrogativas que las Constituciones del Estado de Bolívar consignaban prolijamente, y que tropezaban agresivamente con una realidad que imponía 
su propia dinámica? Significaban, por un lado, que se imponía un tipo de ciudadanía que debía entenderse desde la perspectiva de los derechos, es decir, no solo como derecho a ella, sino como espacio de su ejercicio real y de los deberes correlativos que le eran inherentes. En otras palabras, como el derecho a poseer estos, bajo el entendido de que la igualdad del individuo en dignidad no le es dada per se, si no que sería producto de una severa construcción de la conciencia colectiva desde el acceso a los espacios de discusión pública con base en las libertades (Celso, 1994).

La consagración de una carta garantista les aseguraba a los bolivianos (designación para los habitantes del Estado), la seguridad de que el establecimiento confiaba la certeza de una defensa a prerrogativas sobre las cuales no habría discusión. Un juicio sobre causas ciertas, en los que se defendían principios ciertos, ante instancias reconocidas por las autoridades, reclamaban una innegable certidumbre jurídica, y confiaban la majestad de la justicia a un reclamo imperioso. Esta se abría paso con la denominación de juicio justo según leyes preexistentes y tribunales instituidos de igual forma, siendo la vida, la libertad y la propiedad privada, los valores con más necesidad de ser defendidos. La igualdad ante la ley, que debe ser traducida al campo procesal como igualdad de los procesados frente al procedimiento, revitalizaba la clásica premisa de imparcialidad del juzgador.

Tenemos entonces que esta unidad político-administrativa llamada Estado Soberano de Bolívar, en la que se imponen unas reglas claras con Códigos Civiles y Penales constituyendo normas jurídicas de carácter Sustantivo y de Procedimiento que rigen en todo el territorio en el que tiene jurisdicción -dentro del que se puede castigar su incumplimiento- hace referencia, además, a un principio básico de la Nación moderna como es el desmonte progresivo de las barreras internas.

En un incipiente mercado capitalista, fundado en la defensa a la propiedad privada, todos aquellos instrumentos legales se entendían como mecanismos que podían ser incoados a los jueces, para motivar su expansión y la protección del lucro. La imposición del liberalismo, necesitaba pues de individuos que tuvieran la posibilidad de hacer respetar a través de juicios, la propiedad privada y la generación de sus ganancias ${ }^{6}$. El ciudadano dentro del liberalismo, es pues respetado y su dinero protegido, con el agregado de que pudiera expresar su voluntad de obligarse y de adquirir derechos en el desarrollo de sus gestiones contractuales (Rawls, 1999).

\footnotetext{
${ }^{6}$ Eric Hobsbawm nos dice que la unidad política de los Estados modernos, favorece la unidad social en casos extremos como en la guerra, pero también la consolidación de la economía liberal, ya que puede imponerse a través de reglas claras - normas jurídicas y de procedimientos de justicia - en todo un territorio en que el gobierno puede castigar su incumplimiento. La Nación moderna no tiene barreras internas, por lo cual el mercado capitalista puede perfectamente expandirse y obtener el lucro que desea. Ver: HOBSBAWMN, Eric. Naciones y Nacionalismo desde 1780. Barcelona. Editorial Crítica. S.A, 1991. 206 p.
} 
Luis Edgardo Luna González

La dirección que llevaban estas pretensiones jurídicas, hace intuir la inminente formación de una cultura jurídica en transición, constituida por un conjunto de creencias y opiniones en relación con el derecho, y de forma más concreta, sobre la construcción de este a partir de las representaciones individuales (Friedman, 1975).

Dicha cultura jurídica convierte estos espacios en un nicho para el ejercicio de la ciudadanía, o sea una extensión de la esfera pública (Habermas, 1997). En efecto, estas condiciones están relacionadas con el desarrollo de las ciudades en la América Latina del siglo XIX, en base a la construcción de la relación entre la sociedad civil y el Estado, y el rechazo a las corrientes anti-cosmopolitas (Sábato, 1992: 151).

Estos movimientos en el siglo XIX, significan ni más ni menos, la definición más exterior de la transición entre el Estado antiguo y el moderno. Es en ese momento cuando se percibe que el Estado independiente nacional deja atrás el colonial, y es que cuando se imponen las constituciones federales, las elites criollas se interesan en estructurar uno nuevo con principios de inclusión ante la desaparición del Rey como elemento aglutinador y justificante de la legitimidad. De esta manera, la Nación fue proyectada como una comunidad que se podía imaginar (Anderson, 1993). Pero más allá de eso, fue una comunidad verdadera, que se pudo superponer con ventaja a las otras y asentarse hasta hacerse visible, y además será un artefacto construido a partir de convicciones, fidelidades, solidaridades y virtudes cívicas.

En este sentido Gellner nos propone el concepto de la Nación como el producto de una construcción compleja, en donde continuamente se están enlazando nociones como identidad y cultura predominante, constituyéndose una forma de coexistencia y acomodamiento entre el legado europeo y el colonial (Gellner, 1998). De lo que se concluye que la imposición del Estado liberal respondía a una dualidad entre el concepto de Nación en el sentido antiguo y el moderno (Guerra, 1992:132), dos potencias sorprendidas sin aviso entre las rémoras del clericalismo y la ansiedad caníbal de la juventud, en las que forzosamente -parafraseando a Rafael Gutiérrez G.- se imponía el pensamiento de la nueva época secular (Gutiérrez, 1989. Pág. 63).

\section{Los objetos del poder en la democracia franca}

La idea de un aparato de justicia como poder independiente del ejecutivo y el legislativo, correspondía a la división clásica en términos de Montesquieu, que imponía una severa división de las entidades estatales para evitar la concentración del poder del Estado, procurando así una deseada imparcialidad (Montesquieu, 1999). En términos del liberalismo radical, la idea del establecimiento de un poder público llamado Judicial, representaba a demás, un fuerte símbolo: era la constitución de unos principios 
democráticos, el logro de la protección Estatal de sectores particularmente vulnerables, y la inclusión de los administrados en los asuntos propios del gobierno de la sociedad, y por extensión, la protección de los que habían sido tradicionalmente débiles, en palabras de $\mathrm{N}$. Bobbio (2003).

Esta Administración de Justicia, era reconocida como una facultad manejada por el Estado que buscaba dentro del sistema positivo de normas, aplicar y hacer efectivos a los ciudadanos, los derechos y deberes que les correspondían según estas mismas previsiones jurídicas esencialmente escritas. La seguridad que daba la escritura o consignación de la norma se contraponía con el sistema consuetudinario, y apenas evocaba la tradición legalista colonial.

Este monopolio exclusivo tenía su base en la teoría aplicada en dos cuestiones: La función judicial y la jurisdiccional del Estado. La primera, debía considerarse como la actividad estatal que se manifestaba mediante actos procesales, especialmente la denominada sentencia. Tenemos aquí que es el Estado el que se abroga decidir cuestiones jurídicas controvertidas mediante pronunciamientos que adquieren la calidad de verdad definitiva, que es la verdad procesal. Es esta función la que se invoca para reiterar la resolución de conflictos entre particulares, resolución de conflictos entre particulares y el Estado, castigar la infracción a las normas penales, y defender el principio de legalidad o ajuste de todas las normas a la Constitución vigente, otorgándole al ciudadano seguridad jurídica de que el asunto ha quedado finiquitado. La jurisdicción como órgano del Estado aseguraba entre tanto, la aplicación práctica de las reglas de derecho establecidas, y la constituían el Poder Jurisdiccional propiamente dicho, el poder de decisión ejecutoria y el de cosa juzgada (Naranjo, 1984. Pág. 254-261).

En este orden de ideas, las recopilaciones normativas, como expresión del "espíritu” o ratio legis que impulsó a los legisladores decimonónicos, y que se expidieron desde la segunda mitad del siglo XIX en los Estados Unidos de Colombia, crearon situaciones jurídicas generales como normas de carácter abstracto e impersonal-derecho sustantivo- a las que acudiría el juez individual o corporativo, para desatar los conflictos a ellos sometido por las partes (Cáceres, 1989. Pág. 207-220).

La expedición de Códigos de procedimiento, aseguraba que la conducta del funcionario competente para aplicar la Ley sustantiva se ajustara al querer del legislador y respetara la política del estatuto regulador de las situaciones generales y abstractas. En definitiva, los Códigos de procedimiento regulaban los mismos derechos sustantivos desde el punto de vista de su acción y de la función de quien debía hacerlos respetar. Esta separación obedecía a conveniencias prácticas porque en el fondo se trataba esencialmente de la misma fuente: 
Luis Edgardo Luna González

la libertad y la igualdad jurídica. Esa libertad como noble intención, fungiría en una sociedad decadente, como el último vínculo con la fuerza trascendente de la historia en momentos en que esa modernidad presagiada, era una avalancha de intensiones críticas hacia el sistema (Bell, 1997. Pág. 31-32).

\section{Progresiones: Ley de organización judicial del Estado Soberano de Bolívar}

Los paradigmas descritos en el anterior apartado, fueron el soporte ideológico de la Ley de Organización Judicial (L.O.J) o Ley 22 del 2 de diciembre de 18737 . El sentido de esta Ley era organizar de forma clara, las competencias o atribuciones de las autoridades que administraban justicia. A su vez, constituyó el esfuerzo mejor elaborado, pasados 10 años de la constitución de Rionegro, y resolvía las inconsistencias de las anteriores: la Ley de 16 de octubre de 1868 y las adicionales de 10 de octubre de 1869 y de 14 de octubre de 1871. Es posible rastrear en esta ley el nuevo arquetipo.

El Poder Judicial en el Estado Soberano de Bolívar se encontraba descrito en el Capítulo1 (L.O.J) titulado "División Jeneral" y determinaba que aquel se ejercía de manera privativa por la Asamblea legislativa, El Tribunal Superior de Justicia del Estado, El Jurado de Revisión, Los Jueces de Provincia, Los Jurados Provinciales, Jueces de Distrito, Árbitros y los demás tribunales y juzgados especiales establecidos o que se establecieran por Ley (Articulo 1) ${ }^{8}$.

Tenemos entonces que, dentro de la estructura tripartita del poder público, al Poder Judicial le correspondía la tarea de resolver los conflictos surgidos entre los particulares o entre estos y el Estado, con fuerza de verdad juzgada. La solución final de las contenciones, contaba con las prescripciones generales contenidas en la ley de los Códigos de naturaleza sustantiva o adjetiva. La constitución entonces definía cuales jueces podían Administrar

\footnotetext{
${ }^{7}$ Ley 22 de organización judicial expedida por la asamblea legislativa en sus sesiones ordinarias de 1873. Edición oficial. Cartagena: tipografía Antonio Araujo 1.

${ }^{8}$ La Asamblea Legislativa juzgaba al presidente del Estado o a quien ejerciera sus funciones, al secretario General del Estado, a los Magistrados del Tribunal Superior, al Procurador y al Contador General, por mal desempeño en sus funciones y por delitos comunes (Art. 2\#1 L.O.J). Compuesto de tres magistrados nombrados como prevenía la constitución por el término que en ella se expresaba (Art.3 L.O.J). Las Atribuciones del Tribunal Conocer y decidir en $2^{\mathrm{a}}$ instancia por apelación o consulta de los autos y sentencias pronunciadas en los juicios civiles por los Jueces de Provincia en primera instancia (\#10). Conocer en apelación o consulta de las causas criminales de que conocen y deciden los jueces de provincia (\#11). El Tribunal igualmente cumplía con la atribución del control constitucional de los decretos expedidos en las provincias. (\# 1). Jueces de Provincia: Los jueces de provincia eran competentes para conocer en segunda instancia de las decisiones de los jueces de distrito. Jueces de Distrito: Los jueces de Distrito eran nombrados anualmente por la corporación municipal y su periodo era de un año contado desde el 1 de enero posterior a su elección. Por cada juez de distrito se nombraban tres jueces suplentes que cumplían en su orden los reemplazos: el 1, el 2, y el 3 (Art. 78 y 78 L.O.J).Era obligatorio el ejercicio del encargo de juez principal o suplente en el distrito, cuando el cargo no estaba rentado o su asignación era menor de $\$ 200$ anuales (Art. 82 L.O.J).El juzgado de distrito contaba con un secretario, el cual podía tener o no sueldo según lo determinara la corporación municipal, en todo caso era obligatorio su cumplimiento, por ello quienes desempeñaban estos cargos de juez o secretario estaban exonerados de prestar el servicio personal oneroso (Art. 83,84 y 85 L.O.J).Los jueces de distrito conocían de las demandas cuya cuantía no excedía de \$20, en única instancia y en procedimiento verbal (Art.86 1ª).En primera instancia conocían de demandas en cuantía de $\$ 20$ a \$200 y delitos cuya pena de arresto no fuera mayor de 30 días con multa de $\$ 100$ (Art $862^{\mathrm{a}}, 8611^{\mathrm{a}}$ ).
}

\begin{tabular}{l|l}
\hline REVISTA & $\begin{array}{l}\text { Mario Alario } \\
\text { J'Filippo }\end{array}$ \\
JURIDICA. 12 - No. 23: 81-100, 2020
\end{tabular} 
Justicia. A esta norma constitucional, estaban sujetos la legislación y demás ordenamientos para la implementación del sistema jurisdiccional. Cada juez creado por la Constitución del Estado Soberano de Bolívar, debía su existencia a una calidad especial del individuo o del Estado.

Así pues, el juez civil dirimía con fuerza de verdad juzgada los conflictos entre relaciones privadas y originadas en actos jurídicos contractuales, extracontractuales y las demás fuentes de las obligaciones. El sujeto que define aquí su existencia es el individuo en cuanto parte de relaciones jurídicas civiles. El juez de este individuo es el juez civil, el interés es de orden privado y por ello, renunciable. El individuo en civil se hace titular de derechos personales o patrimoniales, rodeados de garantías a la propiedad privada ${ }^{9}$. La operatividad de la legislación civil se centraba en la protección a esta, con una descripción precisa de las instituciones, en las que se ponía de relieve cierta unidad de criterio, con una técnica de redacción consistente e inteligible, pero que a veces daba lugar a malentendidos ${ }^{10}$.

El juez penal mientras tanto, administraba el derecho penal, el cual respondía constitucionalmente a un interés nacional en cuya defensa se comprometía de forma especial el aparato estatal y la dogmática jurídica. Así se expresa claramente en los apartados de los Informes de Gobernación que corresponden al tema del manejo de la justicia. Dentro de este marco, el derecho penal no desconocía que el delito daña derechos y libertades individuales, por lo cual se estipulaba que el delincuente indemnizara, y el mismo juez podía aplicar la indemnización a petición de parte civil. El juez penal analizaría: conducta, circunstancias personales, circunstancias del hecho, daño causado, interés público lesionado y gravedad ${ }^{11}$.

Como esta actividad de la justicia se visualizaba como un esquema de orden jerarquizado, los asuntos sometidos a ella debían estar vigilados por trámites verticales o sea por los superiores de los jueces de instancias, de tal manera que las actuaciones del a quo (juez inferior) eran controladas por el ad-quem (juez superior). Así las cosas, la competencia de cada juez estaba definida antes del cometimiento de los hechos a él sometidos (juez constituido), y el juez y los procedimientos no solo tenían que conocerse con anticipación, sino que era prohibido el juez ad-hoc o impuesto para un caso particular.

La Ley de Organización Judicial incluyó a los Árbitros como una de las instituciones que ejercían la función jurisdiccional, sin embargo, son pocas las referencias que se hallan al

\footnotetext{
${ }^{9}$ Código civil del Estado Soberano de Bolívar. Edición oficial. Cartagena: Tipografía de Araujo 1884, 395 p.

${ }^{10}$ En cuanto a la legislación de tipo civil, encontramos que se basaba esencialmente en el respeto al derecho de la propiedad privada, como uno de los principios constitutivos de las libertades dentro del esquema liberal radical. La ley de procedimiento civil de diciembre 7 de 1868 costaba de 48 capítulos y 1336 artículos.

${ }^{11}$ Código de procedimiento en los negocios criminales del Estado Soberano de Bolívar. Edición oficial. Bogotá: imprenta de Medardo Rivas, 1873. $139 \mathrm{p}$.
} 
Luis Edgardo Luna González

respecto en la literatura oficial de la época. En este sentido la Ley de Procedimiento Civil de diciembre 7 de 1868, determinaba que en los juicios hechos por árbitros se resolvían controversias sobre asuntos que eran materia de transacción, o sea en los que las partes podían hacer disposición de los derechos sujetos a controversia. Se constituía por un número de miembros que oscilaban entre dos y cuatro personas y una más para dirimir los empates, luego de lo cual se fallaba en audiencia pública y se protocolizaba posteriormente ante un notario.

\section{Corpus IURIS}

El Código Penal del Estado Soberano de Bolívar (Código de los negocios criminales) fue sancionado el 28 de noviembre de 1872, junto con el Código de Procedimiento penal (Código de procedimiento de los negocios criminales), bajo la administración del Gobernador de la Provincia de Cartagena, tercer designado del poder ejecutivo, Manuel Ezequiel Corrales. El primero trata de los delitos -que comprendían las infracciones dolosas o sea la voluntaria y maliciosa violación de la ley, y las culposas como violaciones imputables, pero no maliciosas- y las penas que correspondían a cada infracción; el otro, de los procedimientos para la sanción, comprendía de la investigación de la causa, hasta la sentencia definitiva que absolvía o condenaba al procesado.

Lo que encontramos luego de un análisis minucioso del procedimiento de los negocios criminales, en el estatuto penal del Estado Soberano de Bolívar, es una serie de particulares prerrogativas que en esencia pertenecen al trazado de unos beneficios asignados al ciudadano para protegerlo frente al poder omnímodo del Estado, en un recorrido que es posible reconocer en los informes de Gobernadores y Procuradores desde mediados del siglo XIX, hasta ese desarrollo del año 1872.

El radicalismo liberal acentuó en el citado estatuto el círculo de las garantías procesales, concediendo al individuo una relación de imparcialidad cuando era sometido a un proceso, de tal manera que aquellas se mantenían en directo equilibrio y en el centro de este, en concordancia con los mandatos constitucionales. La ciudadanía se concreta y se blinda mediante la estipulación de distinciones precisas para entender las implicaciones de la imposición del radicalismo liberal en la Administración de justicia, como marco doctrinal y político.

En el siguiente cuadro mostramos la designación de estas mencionadas garantías, para definir en concreto su disponibilidad o uso por parte de los sujetos procesales en las causas o alegaciones jurídicas: 


\begin{tabular}{|l|c|}
\hline \multicolumn{2}{|c|}{ GARANTÍAS DEL PROCESADO } \\
\hline \multicolumn{1}{|c|}{ PRINCIPIOS PROCESALES } & $\begin{array}{c}\text { ARTíCULOS DEL CÓDIGO DE } \\
\text { PROCEDIMIENTO DE LOS NEGOCIOS } \\
\text { CRIMINALES (C. P. N. C.) 1872 }\end{array}$ \\
\hline $\begin{array}{l}\text { Prescripción penal en lo criminal y en lo } \\
\text { civil }\end{array}$ & Artículo 6 \\
\hline $\begin{array}{l}\text { Remisión inmediata del investigado al juez } \\
\text { competente }\end{array}$ & Artículo 17 \\
\hline $\begin{array}{l}\text { Publicidad del proceso para los actores } \\
\text { procesales }\end{array}$ & Artículo 19 \\
\hline Indagatoria sin juramento y sin apremios & Artículo 54 \\
\hline Indagatoria inmediata del investigado & Artículo 59 \\
\hline $\begin{array}{l}\text { Derecho a nombrar defensor de oficio en los } \\
\text { casos previstos }\end{array}$ & Artículo 175 \\
\hline $\begin{array}{l}\text { Detención, pero con orden de funcionario } \\
\text { competente (excepción: personas } \\
\text { aprehendidas en flagrancia) }\end{array}$ & Artículo 80 \\
\hline
\end{tabular}

Cuadro No 1.

\section{Jurados en estrado}

Los referentes conceptuales de estas nuevas formaciones, no eran ni más ni menos que los de las instituciones jurídicas más ampliamente perfeccionadas de la cultura occidental. Ciertamente la aportación conceptual del nuevo derecho que se imponía, promovía entre juristas, comentaristas y público en general, un paralelismo en el que nuestras réplicas, parecían diluirse rápidamente en una notable improvisación, debate nada insustancial.

El concepto era el mismo: garantizar gradualmente su estatus de ciudadano mediante la protección de derechos garantizados, e integrar al individuo base en las tareas de la administración de lo público, y desde esa perspectiva se admitía la necesidad de un experimento social que se constituyera a partir de sumar la incipiente dinámica jurídica cotidiana, y el componente nada despreciable de una cultura rezagada en aspectos como la alfabetización, relacionado con una generalmente poca construida cultura ciudadana incapaz de definir en conjunto, las implicaciones socio - políticas de tal manejo, más aun en un área tan particular como la Administración de Justicia.

Siendo la imposición de los jurados de conciencia una de las expresiones más elaboradas de esto que se asume como la tendencia civilista, su traslado a nuestro país correspondía en principio, a las mismas motivaciones que aquellas esgrimían, siendo obviamente, por las diferencias en cuanto al origen, imposibles de ser homologadas. Sirve ver en este punto las nociones que nos trae el doctrinante Joaquín Escriche, quien para 1890, describía muy bien esos antecedentes en su famoso Diccionario razonado de legislación y jurisprudencia (Escriche, 1872: 486-537). En su apartado sobre el jury (designación por su original en inglés), es posible rastrear, de entre el discurso crítico y de rechazo a que somete la figura 
Luis Edgardo Luna González

de los jurados, los beneficios que le estaban asignados en Europa y Norte América -que él siente como exagerados y sobrestimados- y a los cuales aludían frecuentemente sus defensores en Colombia ${ }^{12}$.

La inclusión de jurados se asociaba con la idea de la exigencia a la comunidad para que condenara ciertos casos de delitos extremadamente lesivos. La constitución de un jurado con un número determinado de personas resulto de la simplificación de los juicios hechos en plaza pública donde era la sociedad u opinión pública, la que manifestaba su decisión con ciertas expresiones o voces de oposición, acuerdo o rechazo, lanzadura de objetos etc., especialmente cuando se trataba de imponer la pena capital. El jurado pues, sintetiza este proceso al ser elegido de entre ciertos miembros representativos de la sociedad para que sean ellos quienes den el veredicto.

Para Escriche era notable que el foco de mucha de la controversia - la cual tendría su propia versión en los Estados Unidos de Colombia - por la imposición de estos jurados, versaba sobre su implementación en detrimento de la jurisdicción de los jueces de derecho. Y es que solía asociarse el orden, transparencia, seriedad y desarrollo doctrinario de la Administración de Justicia, con la existencia de personas estudiosas del derecho, nombradas en sus cargos por el Rey, dada su probidad. Serían justamente estas, las más calificados para entender el juicio en todo su contexto, tanto en la parte fáctica -o sea en el entendimiento de la experiencia de lo ocurrido como hecho criminal- como también de las consecuencias de dicho accionar en el campo legal propiamente dicho, tras el cotejo o examen normativo.

Frente a aquellos se oponían los jurados, catalogados como jueces transitorios, que fallan en conciencia tras el análisis de los distintos puntos de vista de los actores procesales. Escogidos entre los miembros de la comunidad y cumpliendo ciertos requisitos darán su veredicto, más acomodado a la conciencia y al análisis circunstancial de los hechos, que a un examen enteramente legal.

Se establecía que el ciudadano común era juzgado por sus iguales, dando así que se posibilita la pretendida imparcialidad porque se evita una hipotética influencia del soberano a través de los funcionarios que él elige. Aun así, este sistema no era invulnerable, siendo quizá el punto más crítico, el de la falta de idoneidad de los elegidos. El hecho de que el

\footnotetext{
${ }^{12}$ La pertinencia de esta fuente estriba en que surge en pleno auge del radicalismo colombiano y en que muchas de las críticas que ahí aparecen contra los jurados, coinciden con los argumentos más fuertes que se esgrimían en su contra. Una de las referencias a Escriche la encontramos en un comentario del procurador de Estado soberano de bolívar en su informe de septiembre 6 de 1879 en donde se acude a su doctrina para afirmar que "[...] Mientras la pena, como dice Escriche, no tenga otro objeto que el de prevenir los delitos semejantes, quintando al delincuente la voluntad o el poder de repetirlos cuando sin ellas se consiga el fin, será superflua i por consiguiente injusta".
} 
azar escogiera los jurados, propiciaba el problema moral de que algunos fueran juzgados por un grupo de jurados inteligentes y perspicaces, mientras que otros lo fueran por un jurado inepto.

Pero la intencionalidad política de la institución del jurado se desarrollaba en gran medida como el otorgamiento de poderes al ciudadano común para lograr una especie de equilibrio en el cual, no solo el poder ejecutivo ejerciera -a través de nombramientos de juecesinfluencia legítima en el poder judicial y por tanto en los juicios, sino que también pudieran hacerlo aquellos, en una especie de compromiso para involucrarlo directamente en lo público.

Cuando la figura de los jurados se impuso en el Estado Soberano de Bolívar, no pasaría mucho tiempo para que arreciaran las críticas, muchas de las cuales figurarían en los innumerables informes de los Gobernadores, Procuradores, y Magistrados.

La discusión sobre la incorporación de la figura de los jurados para juzgamiento, no pertenecía exclusivamente al ámbito estrictamente penal. Constituía ella, una crítica contra la imposición de instituciones, y la reflexión sobre civilizar la Administración de justicia en Colombia, es decir, cimentar los mecanismos que auspiciaran el mejoramiento de la sociedad para el logro de la paz pública y el progreso, y llevara a las comunidades humanas a un grado ideal de perfeccionamiento en la relación con el castigo de los individuos indeseables.

Dentro de este panorama la institución de los jurados resultó una de las creaciones más reprobadas en el campo judicial: difícil su conformación, difícil el ejercicio real de su competencia, difícil venderla ante la opinión pública como pertinente y eficaz.

Es común señalar entre las faltas más graves de los miembros del jurado, su inasistencia por renuencia a concurrir a las audiencias - y la impuntualidad, causas que agravaban la lid procesal y dilataban los juicios, tras lo cual se proponía el traslado de la sede de Tribunales o disminuir el número de sus componentes. En este sentido se puede traer a colación un famoso caso en los que la equivocación de los jurados pareció a los comentaristas particularmente aberrante ${ }^{13}$.

\footnotetext{
13 "No hace mucho tiempo que una infeliz mujer fue acribillada de heridas con todas las circunstancias de asesinato, a inmediaciones de esta plaza por un malhechor. Este no contento con haber cometido ese horrendo delito le incendio su habitación y le destruyó cuanto en ella había llevado la ferocidad a tal extremo que le asesinó todos los animales domésticos que criaba para su sostenimiento la agredida. El Jurado de acusación declaró que no había lugar de proceder contra el reo; i este quedo por consecuencia gozando de impunidad preparándose sin duda por el aliento que ella le causo a continuar en la carrera de sus crímenes, mientras que la infeliz agredida, en la persuasión de que para ella no hay amparo ni garantía de ninguna, tendrá que huir del país para liberarse del mayor enemigo que si entonces se limitó solamente a causarle varias heridas, ahora llegara a completar la destrucción de su ser; pero si esto es triste i desconsolador, también es digno de horror (sic) recuerdo, que uno de los Jueces de que se componía el Jurado hombre recto e ilustrado conocimiento sus deberes con el omnipotente, i para con la sociedad, se negó a sancionar aquel acto protestó contra él, i se retiró negándole a prestar su firma para que no apareciere en tal escandaloso 
Luis Edgardo Luna González

Otro elemento de no menor importancia, era el fuerte temor a las represalias de los delincuentes, habida cuenta de las frecuentes fugas. La corrupción era un hecho visible y de esto no escapaban los jurados, igualmente reprochados por lenidad o demasiada blandura para dictar el veredicto.

El jurado dentro de la configuración judicial del Estado, era una estructura de ciudadanos elegidos al azar, de listas previamente elaboradas por la Asamblea Legislativa del Estado para que actuaran y dieran sus veredictos en las causas que se seguían por los delitos que causaban mayor conmoción social. De esa manera se afianzaba el vínculo del ciudadano depositario de tal función, con la persecución de los propósitos más fundamentales, expresados como tareas públicas de alto reconocimiento a la que debía acceder con todo rigor (Art. 35-45 L.O.J) ${ }^{14}$.

Es particularmente llamativo como en los informes de Gobernadores y Magistrados, no se desecha la figura en si misma sino más bien se lamenta que no sea aplicada en buena forma, como supuestamente sí lo era - en una perspectiva de sobrevaloración - en pueblos mejor educados que el nuestro, en los que los ciudadanos aparte de sentirse orgullosos de ser elegidos, no eran capaces de traicionar el ejercicio que les competía, ni desequilibrar la balanza de la justicia por causa de rencillas, venganzas, y cualquier otro ánimo corrupto que desviara la auténtica función que se le había encomendado haciéndolo participe de tal tarea. Este eurocentrismo, desplazaba la atención hacia el evento constitutivo de la creación del derecho como agente exterior, e impedía por tradición la evaluación de las posibilidades de una educación dinámica que permeara las estructuras sociales locales para la revitalización del material humano en su aprendizaje efectivo.

El grado de analfabetismo que existía en el Estado, dificultó la creación de una conciencia popular sobre la aplicación de la justicia institucionalizada, a pesar de que el jurado no era una figura enteramente nueva ${ }^{15}$. No se confiaba en la figura, y creaba cierto recelo el hecho

\footnotetext{
fallo". A.H.C. Informe del Procurador General del Estado. Gaceta oficial del Estado soberano de Bolívar. Cartagena, 27 de marzo de $1864 . p p$. $3-4$.

14 El jurado de revisión era elegido por la asamblea legislativa (art. 35 L.O.J). Lo componían 5 miembros y fallaban 7 , teniendo en cuenta que dos de los magistrados principales del tribunal formaban también parte de este jurado (Art. 38 L.O.J). Para elegir a los miembros, la ley de organización judicial (Ley 22 de diciembre 2 de 1873) se hacía una lista que alcanzaba hasta un número de 90 personas escogidas en forma tripartita. El jurado de Provincia No ejercía jurisdicción y resolvían sobre la existencia de ciertos hechos, si los estimaban o no probados, de acuerdo a la convicción intima que en ellos producían los testimonios, documentos y alegatos presentados en el juicio, si estimaban o no probados los hechos sobre los que se le pregunta (Art. 74 L.O.J). Este jurado resolvía sobre el mérito de las diligencias sumarias para someter o no a juicio criminal a determinada persona y sobre el mérito de una causa para condenar o absolver. En el primer caso se llamaba jurado de acusación o revisión y en el segundo jurado de calificación (Art. 76 L.O.J).El jurado de acusación decidía si se había cometido el delito, si había merito para juzgar a la persona indicada (Art. 76 L.O.J).El jurado de calificación decidía si el acusado era responsable, como se calificaba esa responsabilidad y como se graduaba la misma (Art. 76 L.O.J).

${ }^{15}$ La institución del jurado no era ajena a nuestro régimen legal; en efecto, en 1821 el congreso de la Nueva Granada reunido en Cúcuta expidió una ley sobre libertad y juicio de imprenta, con la determinación de que los infractores serían juzgados por un jurado de conciencia compuesto por 24 ciudadano y de cierta independencia económica y mayores de 21 años suficientemente ilustrados. En el artículo 24 se ordenaba al ayuntamiento de cada cantón, tomar la lista. Dicha ley creó, siguiendo el sistema ingles el jurado de causación y calificación compuesto cada uno de siete miembros a la suerte por el alcalde de una lista. Cada vez que se violaba una disposición sobre la materia y se denunciaba ante el alcalde, este buscaba al infractor y lo hacía aprehender. Luego se sorteaba el jurado de acusación y examinados sus miembros para determinar
} 
de que personas de la misma provincia tuvieran la tarea del juzgamiento, situación harto difícil en una sociedad en donde el sentimiento de amiguismo y compadrazgo van más allá del simple sentido de sociabilidad, para convertirse en un valor constitutivo y pieza clave en el sentimiento del ethos costeño, como bien fue descrito por Fals Borda (2002: 91-116). La incipiente cultura jurídica descrita en estos matices explicativos, desafió continuamente la superposición de imágenes y reelaboraciones del Derecho, con las acomodaciones en cada transmisión de los arquetipos políticos.

Frente a tales contingencias, la idea de asimilar la construcción de ciudadanía y el establecimiento de una paz estable a la fortaleza de la Administración de Justicia, parecieran ser ideas inamovibles y fuera de controversia, con las cuales se posibilitaron en el Estado Soberano de Bolívar, los avances más significativos en las luchas más cruentas por la equidad social y el respeto al individuo.

\section{CONCLUSIONES}

La organización de un eficiente poder judicial estatal, es decir, la forma institucionalizada o formal de aplicación de justicia fue presentada por los intelectuales de la segunda mitad del siglo XIX colombiano, como una incuestionable necesidad porque en ella debían residir las pautas para el establecimiento de la paz y el orden. Para que pudiera ser aplicado exitosamente, el orden judicial debía expresar las valoraciones políticas y éticas de un pueblo, y las representaciones más íntimas de la moral, así como de las costumbres y prácticas cotidianas de comportamiento.

La administración de justicia tenía entonces una doble función: hacer efectivos los derechos consagrados en la constitución y las leyes, y al mismo tiempo armonizar esta ejecutoria con las otras ramas del poder público para lograr los fines del estado, en términos de prosperidad y permanencia en el tiempo como aglutinante de la nación. Estas preocupaciones por adecuar la administración de justicia a todo el sistema institucional, de tal manera que actuara como un ente altamente funcional al servicio de la ideología liberal, resultaron verdaderamente significativas para la segunda mitad del siglo XIX, a la manera de una corriente hegemónica.

\footnotetext{
si en ellos había una causal de impedimento legal. Probada su idoneidad se les tomaba juramento y acto seguido, el alcalde se retiraba para que el jurado procediera a calificar la culpabilidad del procesado. El procedimiento criminal siguió encargado a jueces permanentes hasta el año de 1851, en que, por ley de 11 de junio de ese año, se autorizó a la cámara provisional de panamá para que estableciera el jurado que debía conocer de todas las causas criminales, nacionales y extranjeras. Los procesados podían elegir el enjuiciamiento por jurado o por las Leyes comunes de la Republica (Juez de derecho), siempre que así lo manifestaran antes de producirse el sorteo de aquellos. En 1851 bajo la presidencia de José Hilario López, el congreso expidió el 4 de junio ley "estableciendo el jurado para los delitos de homicidio, hurto de mayor cuantía y robo". El jurado se componía de cinco miembros sacados a la suerte de una lista formada por los cabildos. Instalado el jurado, este y el juez de derecho examinaba los testigos que se habían hecho concurrir y después de oír los alegatos de las partes, el jurado de conciencia dictaminaba sobre la existencia o la inexistencia del delito a cabalidad por cuanto no estaban capacitados para analizar los medios probatorios. Igualmente debían calificar la gravedad de la infracción.
} 
Luis Edgardo Luna González

Lo que encontramos en el Estado Soberano de Bolívar, son los esfuerzos de una clase política en transición hacia el liberalismo, obligada a reorganizar lo público como única manera de quedar entronizada dentro de la visión moderna de las sociedades, como ya se veían estructuradas en Inglaterra, Francia y Norteamérica. Estos esfuerzos por crear una sociedad moderna tenían como base la imposición de estado de tipo liberal democrático y la primacía ontológica del individuo, ideas que fueron impulsadas en Colombia por el movimiento radical de la época. Lo anterior significaba un reto enorme sobre todo si tenemos en cuenta el pésimo estado de la hacienda pública, las fuertes tensiones entre los partidos tradicionales, el alto grado de analfabetismo y la consiguiente falta de una cultura política entre el grueso de la población. Todo lo anterior no nos puede llevar sino a afirmar que los conceptos de ciudadanía y democracia aparecen como incipientes idealizaciones de una elite intelectual heredera de la burguesía nacional, con posibilidades de ser educada en Europa, ansiosa por materializar la experiencia liberal en nuestro país, con una feraz interacción entre política y derecho.

Sin embargo, esta panacea de desarrollo económico y moral, no puso en riesgo sus viejos privilegios de clase. Vemos pues una sociedad en desarrollo que le apostaba a un proyecto político-económico determinado, y que en este tránsito a la modernidad adoptara una serie de reformas entre las que se encuentran el modelo de economía liberal, forma federativa de división administrativa y la división tripartita del poder público con independencia de los poderes. Una primera aproximación a la forma que asume el poder judicial de la segunda mitad del siglo XIX, indica una importante consignación de los llamados derechos naturales, en la que el respeto a la vida prevalece de forma explícita.

\section{REFERENCIAS BIBLIOGRÁFICAS}

\section{FUENTES PRIMARIAS}

Ley 22 de 1873. Organización Judicial expedida por la Asamblea Legislativa en sus sesiones ordinarias. Edición oficial. Cartagena: tipografía Antonio Araujo 1.

Código Civil del Estado Soberano de Bolívar expedido por la Asamblea legislativa en las sesiones de 1861 y 1862. Edición oficial. Cartagena: Tipografía de Araujo 1884, 395 p.

Código de procedimiento en los negocios criminales del Estado Soberano de Bolívar. Edición oficial. Bogotá: imprenta de Medardo Rivas, 1873. 139 p.

A.H.C. Informe del Procurador General del Estado. En: Gaceta oficial del Estado Soberano de Bolívar- Cartagena, 27 de marzo de 1864. pp. 3-4. 


\section{FUENTES SECUNDARIAS}

Aguilera Peña, Mario (2001). "La Administración de justicia en el siglo XIX”. En: Revista Credencial Historia. Edición 136, abril. pp. 8-11.

Anderson, Benedict (1993). Comunidades imaginadas: Reflexiones sobre el origen y la difusión del nacionalismo. México: Fondo de Cultura Económica. 315 p.

Bell, Daniel (1997). Las contradicciones culturales del capitalismo. Madrid: Alianza Editorial. Págs. 31-32.

Bentham, J. (1789/1907) An Introduction to the Principles of Morals and Legislation. Oxford: Clarendom Press.

Bobbio, Norberto (2003). Teoría general de la política. Madrid: Editorial Trotta. 779 p.

Cáceres Corrales, Pablo J (1989). Critica constitucional: del Estado liberal a la crisis del Estado Providencia. Bogotá: Banco de la República. pp. 207-220.

Celso, Lafer. (1994). La reconstrucción de los derechos humanos: un dialogo con el pensamiento de Hannah Arendt. México: Fondo de Cultura económica ,388 p.

Critchley, Simón (2008). El libro de los filósofos muertos. Madrid: Taurus.

Escriche, Joaquín (1872). Diccionario razonado de legislación y jurisprudencia. Madrid: Editorial. pp. 486 - 537.

Fals Borda, Orlando. (2002) Historia doble de la Costa. El presidente Nieto. Bogotá: Universidad Nacional de Colombia, Banco de la República. El Ancora Editores. pp. 91116.

Friedman, Lawrence M (1975). The legal system: A social science perspective. New York: Russell Sage Foundation. VII -338p.

Gellner, Ernest (1998). Naciones y Nacionalismos. Madrid: Alianza Editorial. 189 p.

Guerra, François-Xavier (1992). Modernidad e independencia. Madrid: Editorial Mapfre. p.132. 
Luis Edgardo Luna González

Gutiérrez Girardot, Rafael (1989). Temas y problemas de una historia social de la literatura hispanoamericana. Bogotá: Editorial Cavem. pp. 48 - 63.

Habermas, Jurgen. (1997). Historia crítica de la opinión pública: la transformación estructural de la vida pública. México: Editorial Gustavo Gili 352p.

Jimeno Santoyo, Myriam (2006). "Los límites de la libertad ideológica, política y violencia en los radicales”. En Sierra Mejía, Rubén (2006). El radicalismo colombiano del siglo XIX. Bogotá: Universidad Nacional de Colombia. pp. 167-191.

Lemaitre, Eduardo (1983). Historia General de Cartagena. Tomo IV. La República. Bogotá: Banco de la República. pp. 255-262.

López Lopera, Liliana maría (1999). "La ciudadanía miscelánea del liberalismo radical en Colombia”. En: Estudios políticos. No. 14. Medellín, Enero - Junio. pp. 74-104.

Martínez, Fréderic (2001). El nacionalismo cosmopolita. La referencia europea en la construcción nacional en Colombia, 1845- 1900. Bogotá: Banco de la República/Instituto francés de estudios andinos. 580p. https://doi.org/10.4000/bifea.6870

Mayorga García, Fernando (2001). "La administración de justicia en el periodo colonial". En: Revista Credencial Historia. Edición 136, abril. pp. 3-7.

Mendoza C. Alberto (1996). Provincia de Cartagena, Estado Soberano de Bolívar: poblamiento y división política. Sincelejo: Gráficas Lealtad. pp. 186-191.

Montesquieu, Charles (1999). Del espíritu de las leyes. Madrid: Editorial Tecnos. 323p.

Naranjo Meza, Vladimiro (1984). Teoría Constitucional e instituciones políticas. Bogotá: Editorial Temis, p.p. 254-261.

Rawls, John (1999). Justicia como equidad: materiales para una teoría de la justicia. Madrid: Editorial Tecnos.

Sábato, Hilda (1992). "Citizenship, political participation and the formation of the public sphere in Buenos Aires, 1850s-1880s”. En: Past and Present. Agosto. No. 136. 